\title{
Solving of the contradictory problem of the precision- Stability by using the extenics theory
}

\author{
OLARU Adrian ${ }^{1}$ and OLARU Serban ${ }^{2}$ \\ ${ }^{1}$ University Politehnica of Bucharest, Splaiul Independentei nr.313, Bucharest, Romania \\ ${ }^{2}$ S.C.ROMSYS S.R.L. Bucharest, Romania
}

\begin{abstract}
Assisted analyze of the elements and systems with Extenics theory is necessary to choose the optimal value and the optimal minim field called the attraction field of the working point. With this study easily can be determined all influences to the current working point. The Extenics theory was defined by prof.Cai Wen in 1983 and contents the mathematical, philosophy and logical models with the goal to solve the contradictory problem. This paper show the applying the Extenics theory to the optimal choose of the working area of the hydraulic cylinder in the precisionstability field and define some classes of this precision-stability by using the Extenics transformations and dependent functions. The research was made by using the proper virtual LabVIEW instrumentation with the possibility to work on-line and to see all transformation of the dynamic behavior. We established the affiliation of one precision-stability classes by see the changes of the proper form of the dependent function values in the used 2D dimensions. The paper shown the assisted study case of the contraction transformation defining finally the minimal attraction field like the optimized place of the working point.
\end{abstract}

\section{Introduction}

Precision and stability of all dynamic systems is one of the more important contradictory problem what must be solved. This problem is contradictory because if we try to increase the precision, imposed from the application, decrease the stability and will be possible to touch the limit of stability, when the element or system can't be controlling more, otherwise if we try to increase the stability, the precision will decrease and the element or system is very slow and will don't respect the minimal promptitude desired limit. In this situation the Extenics theory must be applied to solve the contradictory problem.

The Extenics theory was created by prof. Cai Wen in 1983 by publishing the paper "Extension Set and NonCompatible Problems"[1]. Its goal was to solve contradictory problem and also nonconventional ideas in many fields like technical, social, philosophical, architectural, etal. Usually the Extenics theory operate with some extension transformation what change the problem from the contradictory field in to noncontradictory by extend the universe of discourse and respect the same value of the dependent function. Some used mining of the transformation [1-3] are substitution, increasing/decreasing, decomposition, duplication and some complex transformation like expansion-duplication, approximation-duplication, substitution- increasing, etal.
Many of the contradictory problem can't be solved by using only one transformation and must be applied many successive or simultaneously transformations.

In the proper paper [4] was defined the minimal attraction field instead of the attraction point established in the paper [5], because in the dynamic behavior all elements and systems don't work only in one singular point, but in one closer field around this point called working minimal attraction field. Attraction points like the optimal working point, defined in [4] was changed in this paper with the working minimal attraction field like to be optimal solution solving the contradictory problem, because in the real work the element and system change his working point in each moment, or by applying the proper dependent formula for 2D dimensions will be not possible to find only one approved situation because will be choose for most of them like full- desirable, partial desirable, partial acceptable, etal. The solution can't be stable, but must be controlled to be inside of one know area established,(desirable, acceptable or compound of them) defined by Extenics theory [1-3] and [6].

In the last proper paper was determined, by applying the basic element and logical equation of the Extenics theory, that the optimal point to solve the contradictory problem precision-stability is the point defined by the $x$ coordinate of the extreme precision point and $y$ coordinate of the extreme stability point. This solution was determined in [5] by applying only the basic 
Extenics logic element was considered that not to be the optimal solution and for that the research was continued with the Extenics extended transformation and with proper defined dependent 2D functions.

In this paper will be applied the extension/contraction Extenics transformation and calculus of the dependent function from Extenics theory [Cai Wen 1983, Yang Chunyan, Cai Wen 2002] with some proper considerations.

The method consist in to determine the new attraction field and calculate the dependent function. If the dependent function is zero, the point is on the boundary field. If the dependent function have other values, the working point can be inside or outside of the desirable or acceptable field. After applying more increasing/decreasing transformation to obtain minimum of the desirable and acceptable field, will be calculated again the dependent function. If the dependent function have the same value, the functional point is in the same class of the precision-stability, in other conditions must be changed his value and will be obtained a higher class of the precision-stability.

With this paper we introduce new term in the study of the optimal solving the precision-stability contradictory problem: the classes of the precision-stability. This operation will be resume more and more before obtained the same class of the working point. The operation will be continue with increasing/decreasing transformation of the current field and with verifying the affiliation at the precision-stability same class.

\section{Study case of the hydraulic cylinder's precision-stability}

\subsection{Modeling and simulation.}

In all study cases the modeling and simulation offer some on-line results what can be used to choose some constructive and functional parameters to obtain one dynamic behavior without vibration, one short acceleration time, minimal stationary error, one bigger Bode frequency, one higher cutting Bode frequency, one higher proper and natural frequencies, etal. In the proper research paper [5] was shown that the Extenics obtained working point is formed by $x$ coordinate of the precision limit point and $y$ coordinate of the stability limit point, because the $y$ coordinate determine the increasing of the proper frequency with effect to the increasing the precision and decreasing the stability and $x$ coordinate determine the increasing of the damper factor with effect to the increasing of stability and decreasing the precision. In this case (partial solving case) the solution of the contradictory problem can be written in the following form $S=\left(\begin{array}{c}x(\text { precision_limitpo int }) \\ y(\text { stability_lim itpo int })\end{array}\right)$ and the compatible degree functions $k(x), k(y)$ and compatible degree of the contradictory problem $K\left(P_{x}\right)$ and $K\left(P_{y}\right)$.

$$
\begin{aligned}
& k(x)=\frac{x-\inf _{-} \lim _{-} \text {goal_} x}{\text { sup_lim_goal_x-inf_lim_goal_x}} ;
\end{aligned}
$$

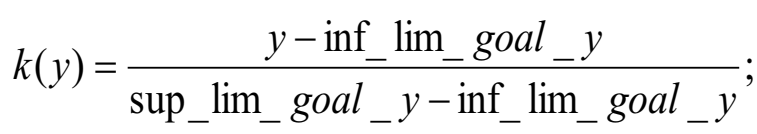

The root's locus characteristic with the desirable field can be seen in Fig. 1.

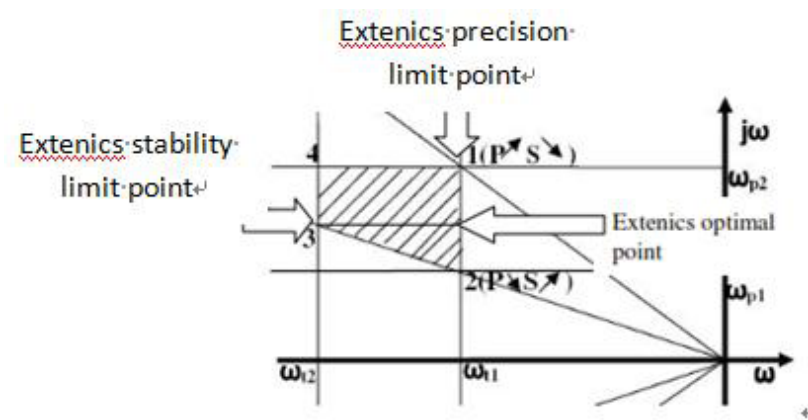

Figure 1. Solution after apply the basic Extenics logical method (partial solution).

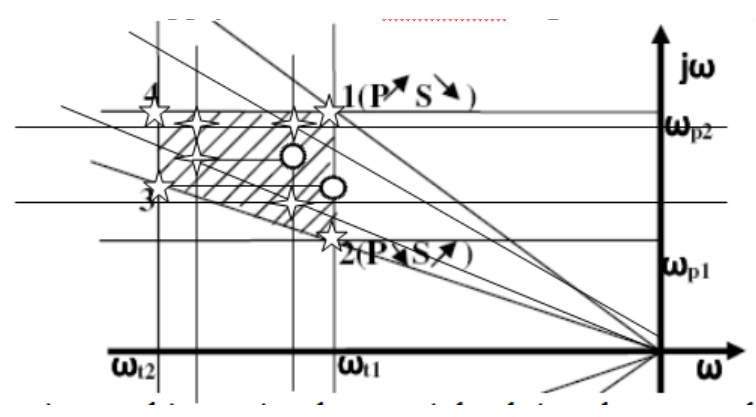

Figure 2. The Extenics working point that partial solving the contradictory problem after applying the Extenics extended/contraction transformation.

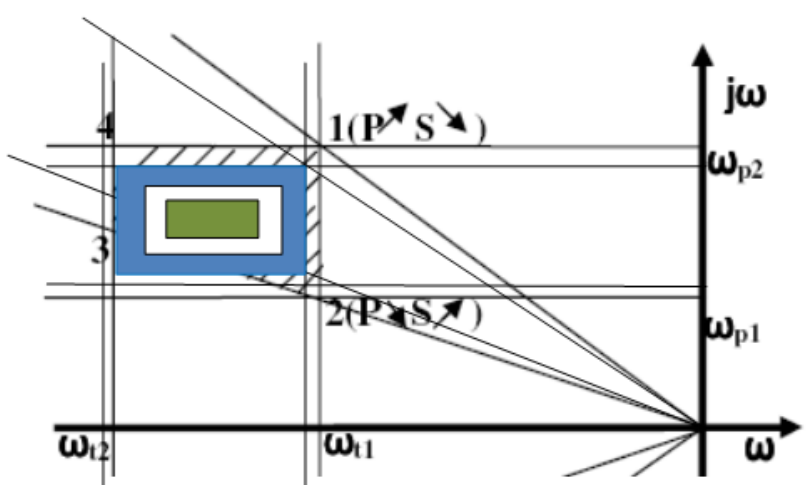

Figure 3. The desirable and acceptable field defined for the study by Extenics $2 D$.

In the modeling step will be used the dependent formula defined in proper paper [6] in the following form: 


$$
k(x, y)=\left\{\begin{array}{l}
k(x) \\
k(y)
\end{array}\right\}=\left\{\begin{array}{c}
\frac{\rho\left(x, X_{0}\right)}{\rho(x, X)-\rho\left(x, X_{0}\right)} \\
\frac{\rho\left(y, Y_{0}\right)}{\rho(y, Y)-\rho\left(y, Y_{0}\right)}
\end{array}\right\}
$$

where: $\rho\left(\mathrm{x}, \mathrm{X}_{0}\right)$ is the distance between the working point $x$ and the desirable interval $X_{0}, \rho(\mathrm{x}, \mathrm{X})$ is the distance between the working point $x$ to the acceptable interval $X$, the same means for the oy axes. The dependent complex formula will be analyzed by logical Extenics theory to choose the optimal point between all analyzed.

\subsection{Extenics transformations and dependent formula.}

Extenics theory use the extended transformation method to change the contradictory problem in one non contradictory. The dependent formula show when the working point is inside or in outside of the imposed, in this case, $2 D$ intervals (desirable and acceptable) what assures optimal solution of the contradictory problem. For this study was used the Extenics contraction transformation [3] of the desirable intervals for $x$ and $y$ axes. Contraction transformation was applied with the reason that working point $(\mathrm{x}, \mathrm{y})$ to be farther from the constraint precision-stability area imposed by the researcher.

Extension/Contraction transformation was applied with $\alpha$ factor for each of axes. About this factor will adapted the $\alpha$ factor that will be applied for all cases studied parameters of the hydraulic cylinder. This factor will be calculated versus limits values for each of the parameters and will be different for all parameters.

$$
\begin{aligned}
& T X_{0}=\alpha X_{0} ; T X=\alpha X \\
& T Y_{0}=\alpha_{0} Y_{0} ; T Y=\alpha Y \\
& \alpha_{i}^{\prime}=\frac{\inf (\lim \text { param.value })_{i}}{\sup \left(\lim . \text { param.value }_{i}\right.} \\
& \alpha_{i}^{\prime \prime}=\frac{\alpha_{i}^{\prime}}{\text { nr.steps }}
\end{aligned}
$$

where $\alpha>1$ for the extension and $0<\alpha<1$ for the contraction what will be applied to the interval $X$ and $Y$, $\alpha$ is the total adapted increasing/decreasing factor and $\alpha$ " is the adapted increasing/decreasing factor for the first step value. Some of the data must be increasing and other decreasing, finally defined the minimal working attraction field [6]. The other way of the research was to define different values of the factor. When the $\alpha$ " $<<1$ will be calculated other value with the condition to respect the step value, all values for increasing or decreasing will be multiplier or de-multiplier with this new value, other will be calculate with $1-\alpha$ " or $1+\alpha$ ".

With the first one way was determined the point $\boldsymbol{P}_{1}$ and with the second one way was determined the point $\boldsymbol{P}_{2}$. The other points were the maximal point of the second research way $\boldsymbol{P}_{3}$, and $\boldsymbol{P}_{4,5}$ the points of the middle of intervals. For each step were applied different values to determine the convergence process. The decreasing factor was determined by de multiply the current factor by around 2. After applying the contraction factor will be obtained the data what are shown in the Table 1 for the first way of the research when the factor was the same for all parameters, like the extension/contraction factor of the field and in the Table 2 are shown the data obtained after applying the different factor for the parameters what is in the condition $\alpha "<<1$. The Extenics transformation will be applied to determine the desirable field for each of the Stability and Precision parameter's values. Each of the current determined field will be the new desirable field and the last one will be the acceptable field in each iteration process. The novelty of the Extenics applied method was to use in the research the different factor for increasing and decreasing values for each of the studied constructive and functional parameters limits and alternating them or each iteration to assure the convergence process and finally to obtain the minimal working attraction field. The value of the transformation factor $\alpha$ " was de multiplied by 2 for each steps, to assure the asimptoticaly neighbour to the minimal attraction field.

Table 1. Data calculated after applied Extenics transformation for the value of $\alpha^{\prime}<1$

\begin{tabular}{|c|c|c|c|c|c|c|c|}
\hline \multicolumn{2}{|c|}{$\alpha=0.1$} & \multicolumn{2}{c|}{$\alpha=0.05$} & \multicolumn{2}{c|}{$\alpha=0.025$} & \multicolumn{2}{c|}{$\alpha=0.012$} \\
\hline $\mathrm{S}$ & $\mathrm{P}$ & $\mathrm{S}$ & $\mathrm{P}$ & $\mathrm{S}$ & $\mathrm{P}$ & $\mathrm{S}$ & $\mathrm{P}$ \\
\hline 91.3 & 85.5 & 86.7 & 89.77 & 88.9 & 87.52 & 87.83 & 88.57 \\
\hline 31.5 & 2.2 & 29.9 & 2.31 & 29.17 & 2.36 & 28.81 & 2.38 \\
\hline 188.1 & 201.3 & 197.5 & 191.2 & 192.5 & 196 & 194.8 & 193.6 \\
\hline 45 & 44 & 42.75 & 41.8 & 41.68 & 42.84 & 42.18 & 42.32 \\
\hline
\end{tabular}

\begin{tabular}{|c|c|c|c|c|c|}
\hline \multicolumn{2}{|c|}{$\alpha=0.006$} & \multicolumn{2}{c|}{$\alpha=0.003$} & \multicolumn{2}{c|}{$\alpha=0.001$} \\
\hline $\mathrm{S}$ & $\mathrm{P}$ & $\mathrm{S}$ & $\mathrm{P}$ & $\mathrm{S}$ & $\mathrm{P}$ \\
\hline 88.35 & 88.03 & 88.08 & 88.29 & 88.16 & 88.2 \\
\hline 28.63 & 2.39 & 28.54 & 2.39 & 28.51 & 2.39 \\
\hline 193.7 & 194.8 & 194.2 & 194.2 & 194 & 194 \\
\hline 42.43 & 42.06 & 42.3 & 42.18 & 42.25 & 42.22 \\
\hline
\end{tabular}

Table 2. Data calculated after applied Extenics transformation for the value of $\alpha^{\prime}<<1$

\begin{tabular}{|c|c|c|c|c|c|c|c|c|c|c|c|}
\hline $\begin{array}{c}\alpha=2 . \\
5\end{array}$ & \multicolumn{2}{|c|}{$\alpha=1.2$} & \multicolumn{2}{|c|}{$\alpha^{\prime}=0.6$} & \multicolumn{2}{|c|}{$\alpha^{\prime}=0.3$} & \multicolumn{2}{c|}{$\alpha^{\prime}=0.15$} & \multicolumn{2}{|c|}{$\alpha^{\prime}=0.07$} \\
\hline $\mathrm{S}$ & $\mathrm{P}$ & $\mathrm{S}$ & $\mathrm{P}$ & $\mathrm{S}$ & $\mathrm{P}$ & $\mathrm{S}$ & $\mathrm{P}$ & $\mathrm{S}$ & $\mathrm{P}$ & $\mathrm{S}$ & $\mathrm{P}$ \\
\hline 1 & 5 & 11 & 6 & 4. & 9. & 3. & 6. & 3. & 5. & 3. & 5. \\
4 & & .6 & & 64 & 6 & 24 & 72 & 72 & 71 & 98 & 31 \\
\hline
\end{tabular}

\subsection{LabVIEW simulation results and discussions of the solving contradictory problem hydraulic cylinder's precision-stability.}

Contradictory problem is one of the more important think to solve in the technical field, because not be possible to design one hydraulic cylinder that can be precise and stable without Extenics solving the contradictory problem.

LabVIEW simulation contents the simulation of the root's locus and dependent formula. After applying the mathematical model of the Extenics dependent function 
for $2 D$ dimension and increasing/decreasing transformations were obtained some results, Figs. 4-7. The Extenics theory was accomplished with the proper remarks and concepts. We remark that the partial solution is not singular and inside of the minimal attraction field and also is not single. For that was applied the dependent formula for more other working points $P_{1}-P_{5}$ what there are very close to this determined area to establish if all these points are in the same precision-stability class or represent the new one precision-stability class. Analyzing the obtained simulation data for the dependent formula, Fig.7 we can remarks the following: all points is in the acceptable- desirable $2 \mathrm{D}$ field, exception, $\boldsymbol{P}_{4} ; \boldsymbol{P}_{\mathbf{1}}$ is the optimal working point determined by Extenics theory. $\boldsymbol{P}_{\mathbf{1}, \mathbf{2}, \mathbf{3}, \mathbf{5}}$ there are in the same precision-stability class by the established desirable- acceptable $2 \mathrm{D}$ fields. $\boldsymbol{P}_{\mathbf{4}}$ is not acceptable point in the precision-stability class. The research can be more precise and for that can be used one new contraction transformation to reduce the acceptable field and will remain inside of the acceptable field only $\boldsymbol{P}_{\mathbf{1 , 2 , 3}}$. These remarks are very important for the researchers to establish very easily and correctly the precision-stability class of the hydraulic cylinder, like was remarked in this study case.

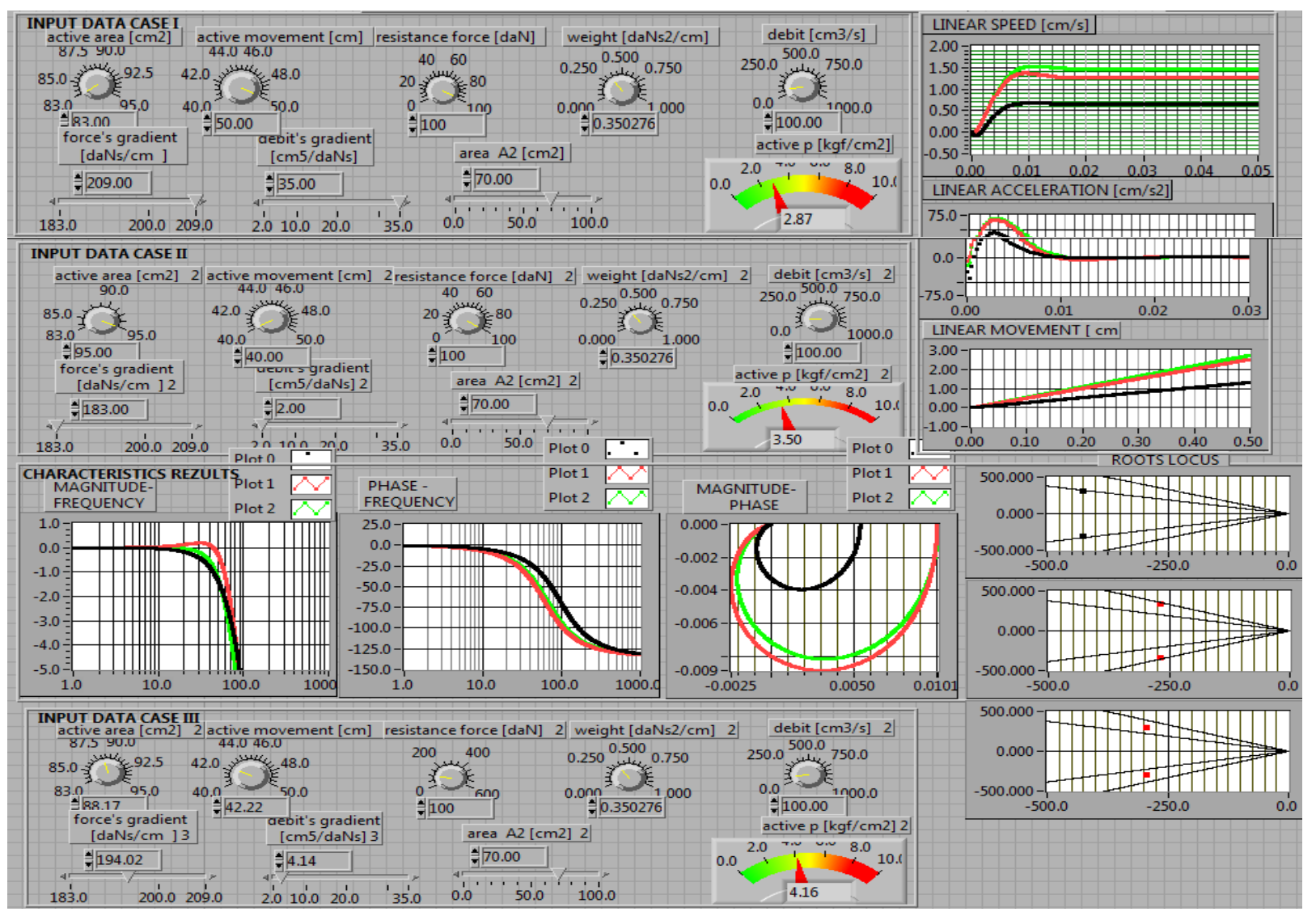

Figure 4. The comparative results with the limits values interval of the precision and stability and the optimal value established after applied the Extenics complex transformation.
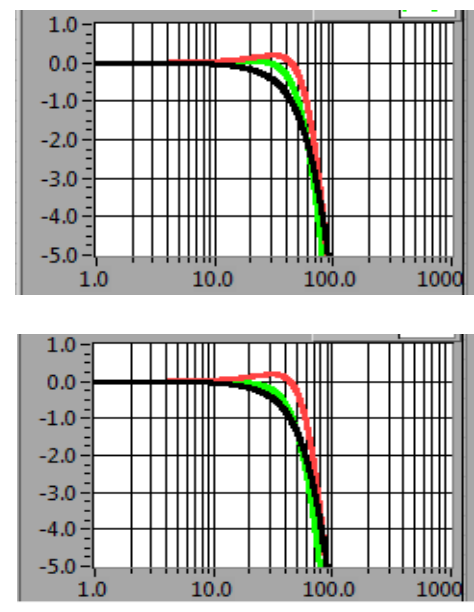

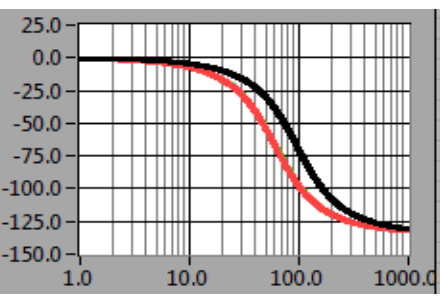

$\mathbf{a}$

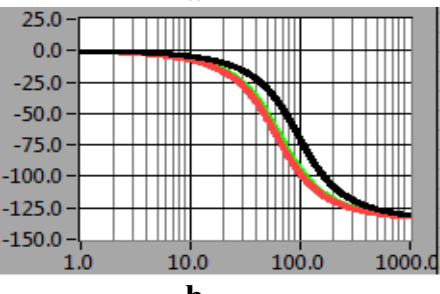

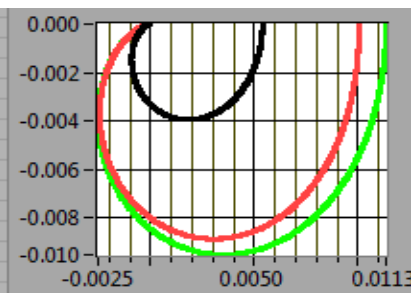

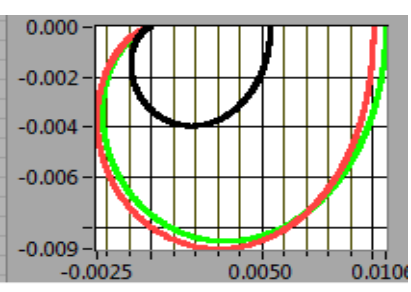



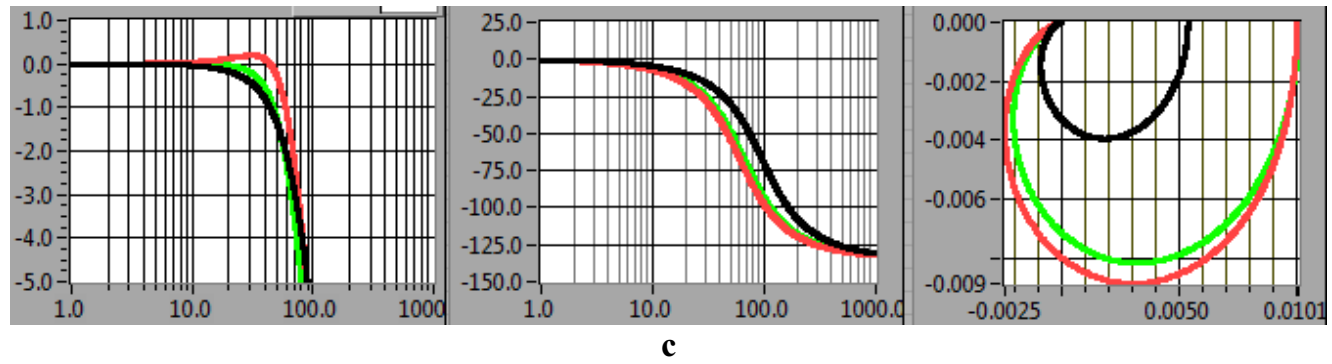

Figure 5. Comparative frequency characteristics Bode and Nyquist with the intermediate and with the final minimal attraction field dynamic behavior established by applying the Extenics theory.
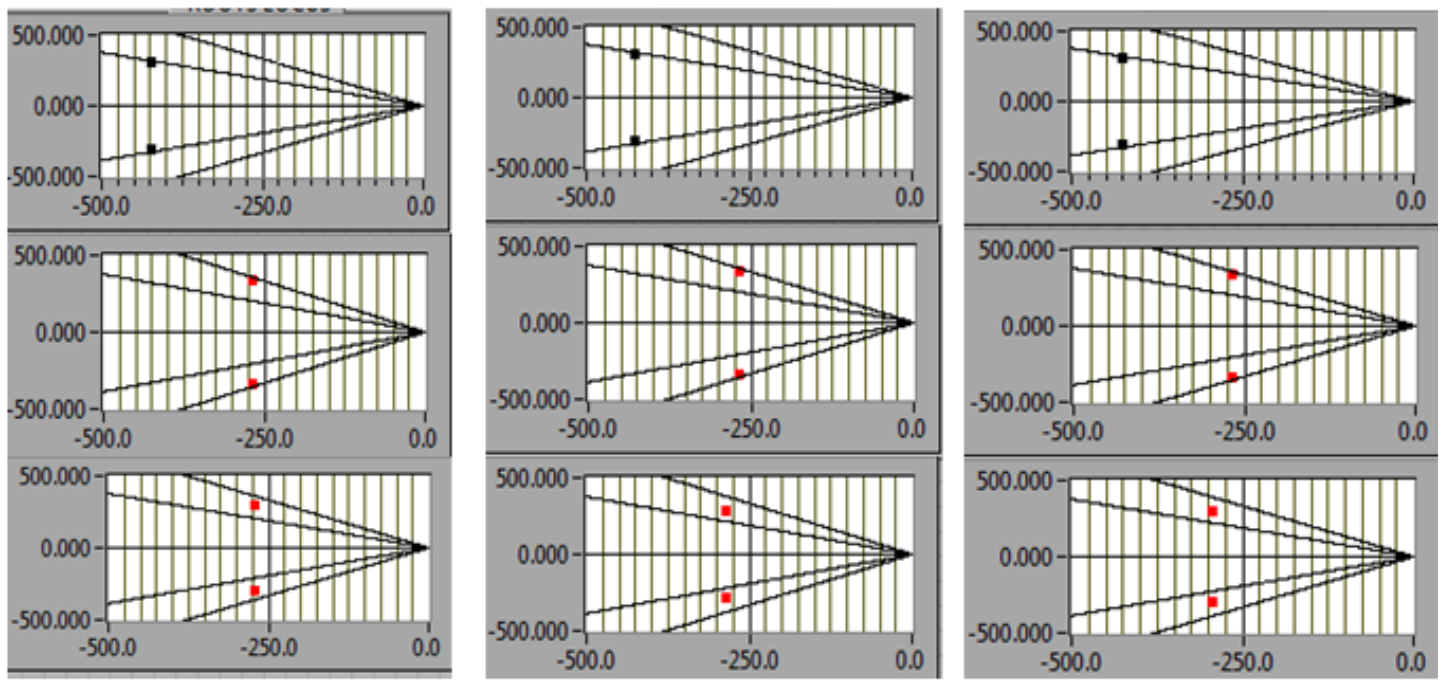

Figure 6. Comparative root's locus for the intermediate and for partial optimal solution after applying the Extenics theory.

The studied points $\boldsymbol{P}_{1-5}$ have the following simulation parameters:

$P_{1}=\left\{\begin{array}{l}88.16 \\ 2.39 \\ 194 \\ 42.22\end{array}\right\} ; P_{2}=\left\{\begin{array}{l}88.16 \\ 3.98 \\ 194 \\ 42.22\end{array}\right\} ; P_{3}=\left\{\begin{array}{l}88.16 \\ 5.31 \\ 194 \\ 42.22\end{array}\right\} ; P_{4}=\left\{\begin{array}{l}88.16 \\ 20 \\ 194 \\ 42.22\end{array}\right\} ; P_{5}=\left\{\begin{array}{l}88.16 \\ 15 \\ 194 \\ 42.22\end{array}\right\}$

where the data means: aria $\mathrm{A}=88.16\left[\mathrm{~cm}^{2}\right]$; flow gradient $\mathrm{a}_{\mathrm{m}}=2.39 ; 3.98 ; 5.31 ; 20 ; 15\left[\mathrm{~cm}^{5} / \mathrm{daNs}\right] ;$ force versus velocity gradient $b_{m}=194[\mathrm{daNs} / \mathrm{cm}]$; active movement $\mathrm{c}=42.22[\mathrm{~cm}]$. After applying the Extenics theory and the assisted determination of the dependent $2 D$ formula for each of these points, we were obtained the results from (5). The applied values were determined by apply the logical Extenics theory with AND function between the goals and conditions matter-elements[5].

The values of the point's parameters were obtained by convergence process of the Extenics transformation and after applying $\min$ (precision_value, stability_value)function.

$$
\begin{aligned}
P_{1} & =\left\{\begin{array}{l}
286,556 \\
286,979
\end{array}\right\}\left\{\begin{array}{l}
k_{1}(x)=-0.025 ; k<0 \Rightarrow x \in X \\
k_{1}(y)=0.03 ; 0<k<1 \Rightarrow y \in Y_{0}
\end{array}\right\} \Rightarrow \text { acceptable_desirable_point } \\
P_{2} & =\left\{\begin{array}{l}
292,964 \\
286,979
\end{array}\right\}\left\{\begin{array}{l}
k_{2}(x)=0.145 ; 0<k<1 \Rightarrow x \in X_{0} \\
k_{2}(y)=-0.100 ;-1<k<0 \Rightarrow y \in Y
\end{array}\right\} \Rightarrow \text { desirable_acceptable_point } \\
P_{3} & =\left\{\begin{array}{l}
298,324 \\
297,505
\end{array}\right\}\left\{\begin{array}{l}
k_{3}(x)=0.288 ; 0<k<1 \Rightarrow x \in X_{0} \\
k_{3}(y)=-0.208 ;-1<k<0 \Rightarrow y \in Y
\end{array}\right\} \Rightarrow \text { desirable_acceptable_point } \\
P_{4} & =\left\{\begin{array}{l}
358.773 \\
340.217
\end{array}\right\}\left\{\begin{array}{l}
k_{4}(x)=-0.21 ;-1<k<0 \Rightarrow x \in X \\
k_{4}(y)=-1.195 ; k<-1 \Rightarrow y \notin Y_{0}, Y
\end{array}\right\} \Rightarrow \text { acceptable_nonacceptable_point } \\
P_{5} & =\left\{\begin{array}{l}
338,623 \\
327,842
\end{array}\right\}\left\{\begin{array}{l}
k_{5}(x)=0.175 ; 0<k<1 \Rightarrow x \in X_{0} \\
k_{5}(y)=-0.909 ;-1<k<0 \Rightarrow y \in Y
\end{array}\right\} \Rightarrow \text { desirable_acceptable_point }
\end{aligned}
$$




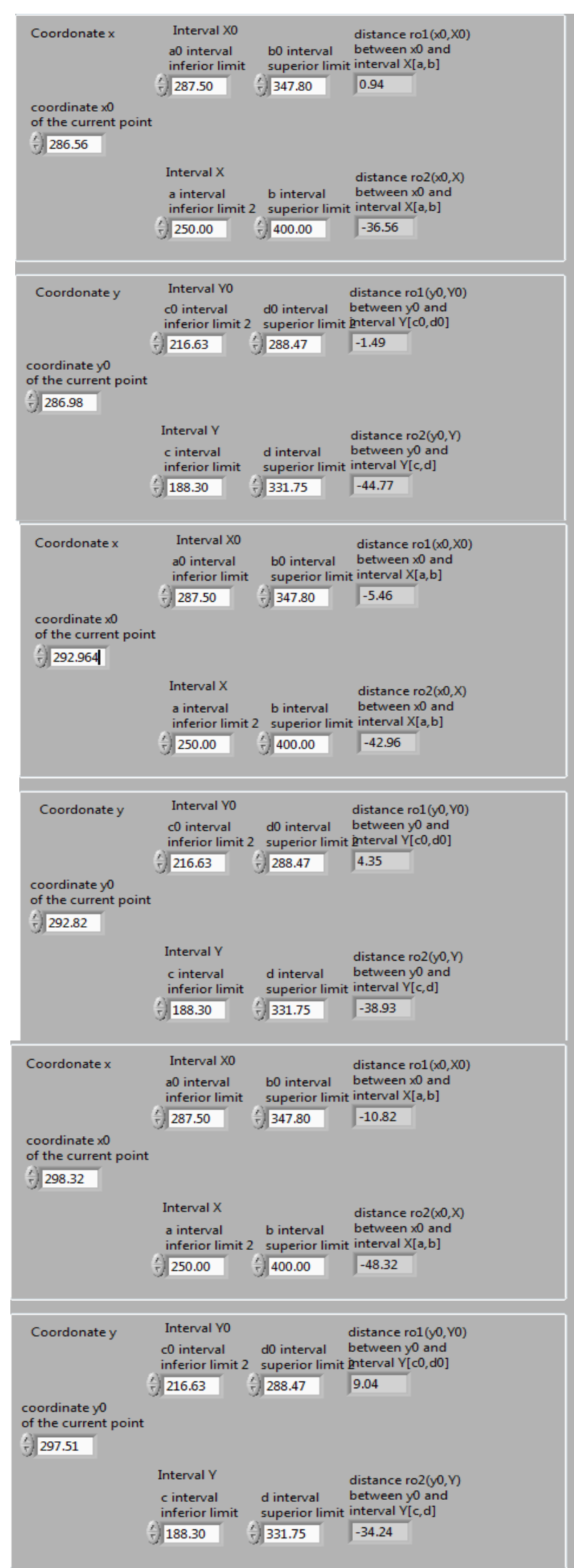

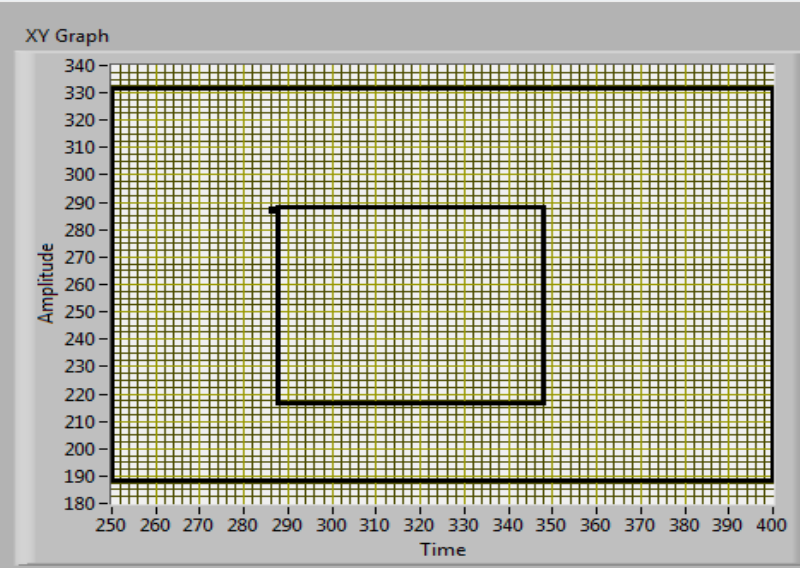

$\begin{array}{lll}k(x) & \text { if } \quad k()<-1 x \text { or } y \text { is outside of the acceptable space; } \\ -0.02517 & \text { if }-1<k()<0 \text { or } y \text { is in the accepted space; }\end{array}$

$-0.02517 \quad$ if $-1<k()<0$ or $y$ is in the accepted space;

$\begin{array}{lll}k(y) & \text { if } 0<k()<1 \times \text { or } y \text { is inside of dessirable space; }\end{array}$

0.03445 if $k()=-1 \quad x$ or $y$ is on the acceptable boundary

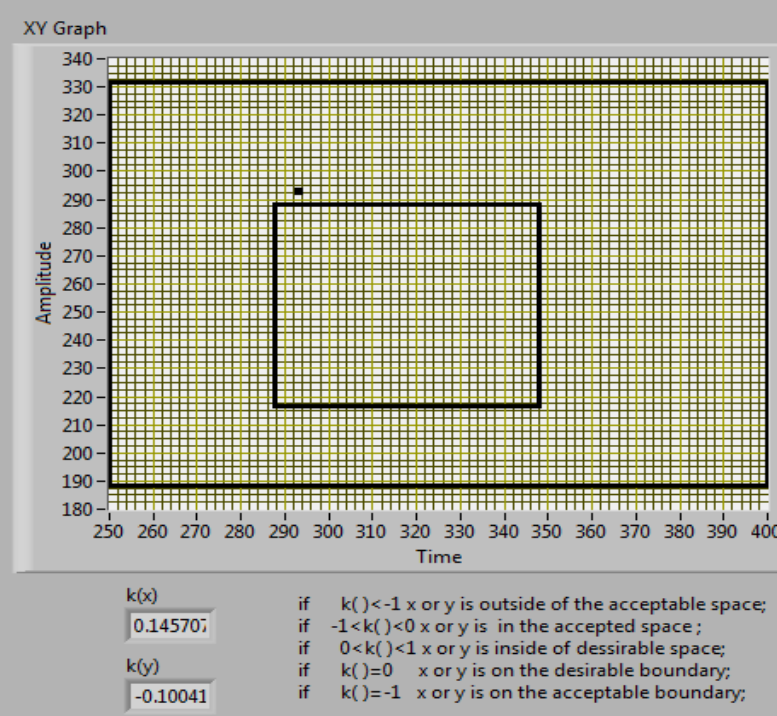

XY Graph

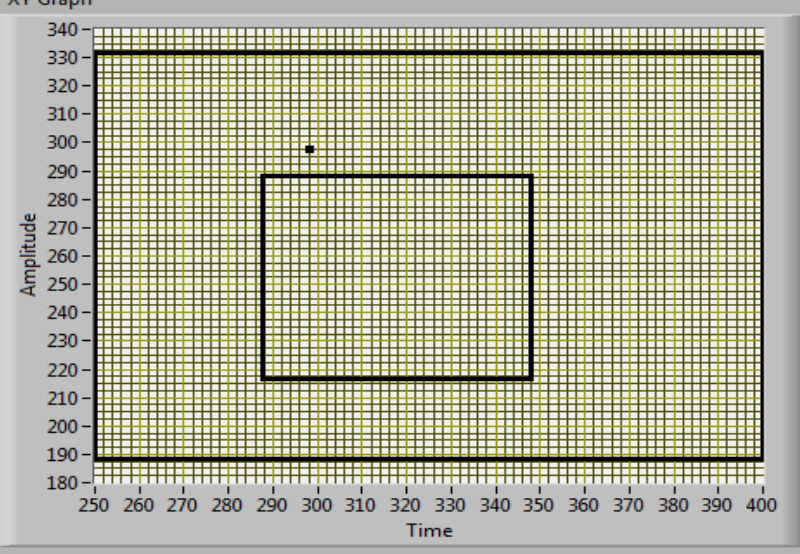

$k(x)$

\begin{tabular}{|c|c|c|}
\hline$k(x)$ & & $k()<-1 \times$ or $y$ is outside of the acceptabl \\
\hline $0.28864 \mathrm{C}$ & & $<k()<0 x$ or $y$ is in the accepted space; \\
\hline$k(y)$ & if & $0<k()<1 \times$ or $y$ is inside of dessirable space; \\
\hline-0.20887 & if & $\mathrm{k}()=-1 \mathrm{x}$ or $\mathrm{y}$ is on the acceptable boundary; \\
\hline
\end{tabular}




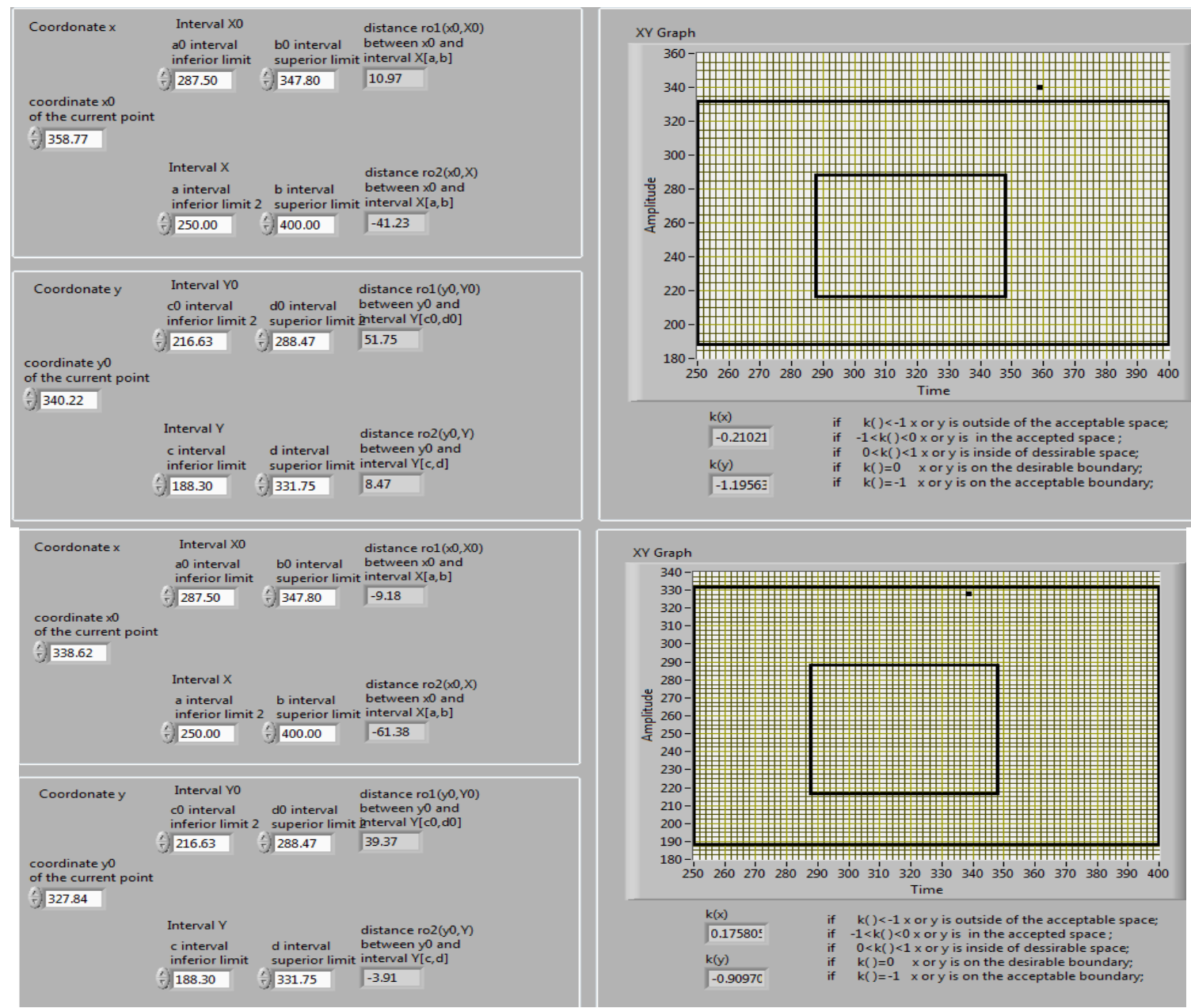

Figure 7. The desirable and acceptable fields and determined depend $2 D$ formula for the all working researched points $P_{1}-P_{5}$.

We can define 9 classes of the acceptable, desirable and complex acceptable-desirable and non-acceptable fields of the Extenics theory in 2D dimensions modeling of the dependent function.

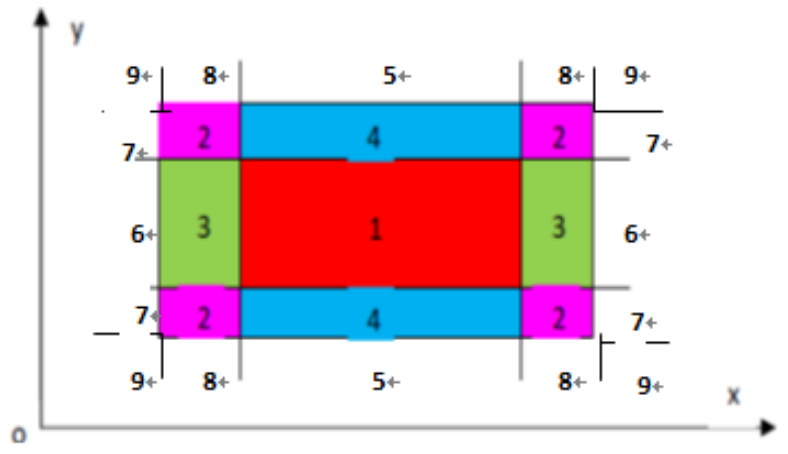

Figure 8. The desirable and acceptable fields in the $2 \mathrm{D}$ dimensions of Extenics.

1-Full desirable $\left\{\begin{array}{l}x \Rightarrow \text { desirable } \\ y \Rightarrow \text { desirable }\end{array}\right\} ;$
2- Full acceptable $\left\{\begin{array}{l}x \Rightarrow \text { acceptable } \\ y \Rightarrow \text { acceptable }\end{array}\right\} ;$
3- Partial acceptable $\left\{\begin{array}{c}x \Rightarrow \text { acceptable } \\ y \Rightarrow \text { desirable }\end{array}\right\}$;

4- Partial desirable $\left\{\begin{array}{c}x \Rightarrow \text { desirable } \\ y \Rightarrow \text { acceptable }\end{array}\right\}$;

5-Partial acceptable $\left\{\begin{array}{c}x \Rightarrow \text { desirable } \\ y \Rightarrow \text { nonacceptable }\end{array}\right\}$;

6-Partial acceptable $\left\{\begin{array}{c}x \Rightarrow \text { nonacceptable } \\ y \Rightarrow \text { desirable }\end{array}\right\}$;

7- Partial acceptable $\left\{\begin{array}{c}x \Rightarrow \text { nonacceptable } \\ y \Rightarrow \text { acceptable }\end{array}\right\}$;

8- Partial acceptable $\left\{\begin{array}{c}x \Rightarrow \text { acceptable } \\ y \Rightarrow \text { nonacceptable }\end{array}\right\}$;

9- Full nonacceptable $\left\{\begin{array}{l}x \Rightarrow \text { nonacceptable } \\ y \Rightarrow \text { nonacceptable }\end{array}\right\}$ 


\section{Conclusions and future work}

By applying the extended transformation and dependent formula for $2 \mathrm{D}$ were obtained the optimal results what solve the contradictory problem. The applied method LW instrumentation assures the precise results and validate some of Extenics relations. The obtained results, the applied method, all LabVIEW instrumentation and all remarks about $2 \mathrm{D}$ classes assures for the research the way for solving better the contradictory problems. For the future will be applied the complex extension transformation method and extension strategy generating system.

\section{References}

1. W. Cai, The Extension Set and Non- compatible Problems, Editor W. Z. Chien, AMM in China, International Academic Publisher, 2, 1-21, (1990).
2. W. Cai, Matter-element Models and Their Applications, Beijing: Science and Technology Document, Publishing House, (1994).

3. C. Y. Yang, and W. Cai, Extenics: Theory, Method and Application, Science Press, China, (2002).

4. A. Olaru, Optimal Solving of the Contradictory Problem between Hydraulic Cylinder's Precision and Stability with Extenics Theory, ICMAE2013, Proceedings, Moskow, 2013.

5. Florentin Smarandache, Generalization of the Distance and Dependent Function in Extenics to 2D, $3 D$ and $n D$, Science and Technology Document, Publishing House, (2012).

6. A. Olaru, Assisted Analyze of the Extenics Dependent Functions in 1D,2D,3D and nD Dimensions with LabVIEW Instrumentation, ICNCT2013, Proceedings, Seul, 2013. 